\title{
Global Trends In The Commercialization Of Space
}

Joseph A. Giacalone, St. John's University, USA

\begin{abstract}
For the past half century, the commercial potential of space has been a major rationale for the space program in the United States and elsewhere. This paper will provide an overview of spacerelated industries, which accounted for global revenues in the range of $\$ 106$ billion by 2006, and the drivers that impact their development. It incorporates the evolution of space policy, recent economic data, and the emergence of the private spaceflight industry.
\end{abstract}

\section{INTRODUCTION}

n January 2004, President George W. Bush presented his "vision" for the U.S. space program. It was the latest in the string of such presidential declarations dating back to the term of John F. Kennedy. Bush's vision declared that a vibrant space program was critical to the scientific, political, and economic interests of the United States. As such, President Bush laid out an agenda that would involve robotic and manned missions to the moon, Mars, and beyond.

Certainly, to those whose fantasies are excited by the Star Wars and Star Trek genre of science fiction, this was good to hear though not the first time they had heard it. Indeed, man has been fascinated with the possibility of space travel and human settlement of the moon and planets throughout history (Veenaskay and Muakasa, 1988). The visibility of the starlit sky from everywhere on earth provided humans with a view of space that has sparked ready speculation as to its potential.

To the skeptics, the vision was blurred and dimmed by the belief that the required resources for exploration and commercial exploitation were not available despite political assurances to the contrary. Moreover, some believed that even if the resources were available, space exploration should have a lower priority than many other national and global needs.

To those already involved in "commercial space", the message was one that they hoped would accelerate the pace of economic exploitation that had barely begun to tap its potential. The President's vision offered some modest additional funding for the National Aeronautics and Space Administration, an invitation for international participation, and the creation of a Commission to make recommendations on the direction of the U.S. space program, including the commercialization of space. The Presidential Commission on Implementation of United States Space Policy was established by executive order and chartered on February 2, 2004 with a mandate to make its recommendations within 120 days. The report was delivered on June 4, 2004.

\section{REPORT OF THE PRESIDENTIAL COMMISSION}

As mentioned above, the Presidential Commission on Implementation of United States Space Exploration Policy was established by executive order in January 2004 by President George W. Bush to examine the future of space exploration in the context of his administration's "vision." Its report (Presidential Commission, 2004) gave strong support to commercialization efforts and increased privatization of the whole space program. It affirmed the existing trend of contracting out many NASA activities to the private profit and not-for-profit sectors. The Commission called for a reorganization of NASA to reduce its extreme bureaucratic management of the nation's space program. It recommended that the private sector be given primary responsibility for all lower earth orbit 
(LEO) activities and encouraged private contests, such as the Ansari X-Prize, as inducements for space ventures. NASA would be given primary responsibility for manned and unmanned exploration beyond the earth and developing space technology which would be too expensive and/or too risky for the private sector. Overall, the Commission called for a streamlined NASA that would provide more efficient support for privatized operations and commercial development.

\section{U.S. NATIONAL SPACE POLICY}

A new national space policy was authorized by the President on August 31, 2006. This policy reaffirmed the U.S. commitment to the peaceful uses of space, the advancement of commercial space activities, and the promotion of international cooperation in various space-related endeavors. The policy delineated a series of key principles one of which explicitly commits the country to "encouraging and facilitating a growing entrepreneurial U.S. commercial space sector" and "...the use of U.S. commercial space capabilities to the maximum practical extent, consistent with national security." A fundamental goal will be to "enable a dynamic, globally competitive commercial space sector in order to promote innovation, strengthen U.S. leadership, and protect national, homeland, and economic security." The policy document includes a six-point section that lays down specific commercial space guidelines. Government departments and agencies are encouraged to purchase and use commercially available space capabilities or help modify existing commercial systems to meet government requirements. Importantly, agencies and departments are discouraged from deterring or competing with commercial space activities. Moreover, the government entities are encouraged to make their technology and infrastructure available for commercial use on a reimbursable basis. And, finally, the policy calls for the maintenance of a "timely and responsive" regulatory environment for licensing commercial space activities. For the most part, responsibility for U.S. commercial space activities is assigned to the jurisdiction of the Department of Commerce although other government departments could be involved. Not surprisingly, though the national policy encourages international cooperation on peaceful commercial developments, it reserves all rights where national security is involved. This is pretty much the standard reservation for governments around the world.

\section{THE CURRENT STATUS OF SPACE INDUSTRIES}

\section{Industry Categories And Components}

The major categories of space industries are satellite communications, space transportation, global positioning systems, and remote-sensing. Each of these major categories encompasses several sub-industries. Satellite communications includes satellite services, transponder leasing, ground equipment manufacturing, and satellite manufacturing. Space transportation involves primarily commercial launch operations and vehicle manufacturing. The key component of the remote-sensing category is satellite imaging systems although the segment also includes aerial imaging and geographical information systems. The Global Positioning System (GPS) is a U.S. Department of Defense deployment of satellites and ground support stations that serves both military and civilian applications. The civilian markets include in-vehicle navigation for air, land and sea vehicles, recreational navigation, and various forms of surveying and timing applications.

\section{Data Considerations}

Systematic collection and timely availability of data on the quantitative dimensions of space-related industries is still in its early stages. The data reported in the following sections are largely based on Trends in Space Commerce, a report commissioned by the U.S. Department of Commerce's Office of Space Commercialization. It was prepared by the Futron Corporation and released in 2002. This report was supplemented with Satellite Industry Association's Satellite Industry Statistics 2002 and The State of the Satellite Industry Report released in June 2007. The SIA data is derived from its periodic surveys of space industry firms worldwide conducted in conjunction with Futron. Where appropriate, both reports incorporate data from more established public and private data sources. A major data challenge is to filter out military activities from commercial efforts. Though the statistical reliability of the data may be less than optimal, the data are satisfactory for the purpose of showing various aspects of the size and direction of commercial space activity. 
Revenues, Employment, Growth, and Driving Forces, 1996-2002

The main data series involve the revenues produced by companies in the various components of the space industry. Growth rates are expressed in terms of changes in annual revenues. Employment data is expressed in number of employees engaged by the firms in their respective industries. In both revenue and employment, the data relied on in this paper separate the United States from the rest of the world. In examining driving forces and trends, worldwide developments are considered.

\section{Satellite Communications}

Retail/subscription satellite services, transponder leasing, satellite manufacturing, and ground equipment manufacturing are the components of this industry. These various components generated global revenues estimated to be almost $\$ 89$ billion dollars in 2002 and about $84 \%$ of total space industry revenues.

The satellite services segment of the industry contains rapidly growing, direct-to-consumer content including direct-to-home television, direct radio, wireless telephones, and data services. The latter has been fed by the explosive growth in the use of the internet which has benefited from the move to broadband connections. In the United States, names like the Dish Network, Direct TV, Sirius Satellite Radio, and XM Satellite Radio are quite familiar. Between 1996 and 2002, satellite services grew from $42 \%$ to 57\% of total revenue with almost $\$ 50$ billion in various subscription and retail services. The overall satellite communication industry has benefited significantly by the global deregulation of telecommunications markets.

From 1996 to 2002, retail/subscription satellite service revenues grew from $\$ 3.34$ billion to $\$ 12.47$ billion in the U.S. and from 7.12 billion to 24.17 billion in the rest of the world. This rapidly growing sector saw significant employment growth during the period, rising from 8,700 to over 27,000 employees worldwide, with the U.S. accounting for $62 \%$ of the sector's labor force.

The various pieces of ground equipment needed for the provision of satellite communications, including items like TV dishes and receivers, telephone and data units, and specialized terminals, generated 2002 revenues of over \$20 billion, with the U.S. holding about two-thirds of the market. Worldwide ground equipment manufacturing revenues should track closely to the growing satellite services sector. The manufacturing of all this equipment provided 2002employment to over 54,000 persons, 24,900 of which were in the United States.

As of 2002, there were almost 500 operational communications satellites in orbit. The manufacturing of these satellites provided worldwide employment to almost 117,000 persons, including about 52,000 in the U.S. Worldwide revenue from satellite manufacturing, exclusive of military satellites, approximately doubled between 1996 and 2002 to almost \$19 billion. U.S. manufacturers are facing growing competition from foreign manufactures. The manufacture of satellites for deployment in lower earth orbit (LEO) received a setback from the bankruptcies of Iridium and Globalstar in 1999. Both systems are still operational as Globalstar emerged from chapter 11 and Iridium's assets were purchased and returned as Iridium Satellite. However, a more cautious approach is being followed.

Telecommunications and data relay firms require access to satellite transponders to relay their signals. Transponders refer to the package of equipment on board the satellite that amplifies the original signal and relays it back to the receiver on earth. Satellite operators sell or lease such transponder capacity. Transponder leasing generated almost $\$ 12$ billion in 2002 revenue, up from $\$ 5.2$ billion in 1996, a healthy 230\% increase. The U.S. share of industry revenues amount to $32 \%$ or $\$ 3.82$ billion in 2002 . Employment in the transponder leasing sector was estimated at over 11 thousand employees worldwide in 2002. The U.S. employed about 3800 in 2002 , a gain from just 900 in 1996. The growing demand for transponder capacity by information distributors of Internet content is a positive factor for this market. 


\section{Global Positioning Systems}

This component of the space industry accounted for about $9 \%$ of overall industry revenues in 2002 . The manufacture of various types of hardware and software equipment constitutes the major parts of the GPS industry. Industry revenues earned by GPS producers were estimated to be almost $\$ 9.5$ billion in 2002 with the United States accounting for about $50 \%$ of the total. The U.S. share of revenues declined from about $66 \%$ in 1996 . Worldwide sales of commercial GPS units sold between 1996 and 2002 rose from approximately 1.5 billion to over 5.6 billion. The projection for worldwide GPS employment in 2002 was approximately 46,500 persons.

All aspects of land, marine, and air travel have adopted GPS technology. Passenger car units, cell-phone units, and units for recreational use such as boating and hiking have been among the more consumer-oriented applications serving navigational and locational functions. Car navigation units accounted for almost $35 \%$ of the market in 2000 with other consumer applications representing $22 \%$ of unit sales.

As mentioned above, the current GPS industry depends on the deployment of 28 satellites and ground support facilities by the U.S. Department of Defense. The system was designed originally to provide precise positioning and timing information for military purposes. However, GPS has found a wide variety of consumer applications as GPS units have been incorporated into high value-added consumer products such as automobiles and cellular phones. In 1998, the European Space Agency had indicated its intent to create its own system, named Galileo. In June of 2004, the United States and the European Commission reached an agreement aimed at assuring cooperation between the two systems when Galileo is eventually completed (White House 2004). The need for such an agreement was precipitated by concerns that signal interference between the two systems might cause mutual national security problems. The agreement provides for the mitigation of such concerns. The Galileo system has made minimal progress to date, primarily due to serious financial constraints. Public funding has replaced the originally anticipated private financing. In April of 2008, the European Space Agency launched the second of the thirty satellites slated for deployment in its system. If all goes according to the current plan, completion would be in the middle of the next decade.

It has been reported (NYTimes, April 4, 2007) that Russia is close to completing Glonass, Global Navigation Satellite System, with its expected launch of eight navigation satellites late in 2007. Initially, it would operate over Russian territory and parts of adjacent Europe and Asia. Russia expects it to go global in 2009 to compete with the US GPS system. This would break the US monopoly on satellite navigation. Furthermore,

the People's Republic of China is also developing its own system, called Baidu.

The Russian system does possess some marginal technical improvements over the GPS system of the US. This raises the issue of whether or not devices should have dual capability, at least those devices used for commercial purposes. For the most part, it would appear unnecessary for such capability on consumer devices though some might want the extra capability and would pay a premium for it.

Satellite navigation systems are a rapidly expanding industry. According to the GPS Industry Council, the global market for GPS devices reached $\$ 15$ billion in 2007, expanding at the rate of 25-30 percent annually. Military considerations aside, the deployment of multiple positioning systems offers promise of expanded commercial opportunities in the future.

\section{Space Transportation}

Space transportation has received some very exciting attention recently with the first two instances of space tourism conducted by the Russian space agency (Leonard, 2001) and the X-Prize competition (Thorpe, 2003; Schwartz 2004) designed to stimulate privately financed space travel. In the first instance, the Russians transported American Dennis Tito (2001) and South African Mark Shuttleworh (2003) to its portion of the International Space Station for a price of $\$ 20$ million a flight. Three other private citizens have subsequently flown on Russian space missions as paying customers. The high price was not set to stimulate widespread consumer demand but to help 
support the cash-strapped Russian space program. Recent news from Russia indicated that it might suspend such trips after 2009 due to the lack of available seats.

On the other hand, the Ansari X-Prize competition offered an award $\$ 10$ million to the first privately financed space vehicle that can carry three persons to an altitude of 100 kilometers on two trips within three weeks of each other before January 1, 2005. The successful completion of this feat is considered to have more realistic potential for the development of a private, reasonably priced space tourism market. The prize was claimed by Burt Rutan and SpaceShipOne in 2004. Rutan's success has provided a major stimulus to the private space flight industry which will be discussed later in this paper. An aspect of space transportation where Russia has taken the lead is in space advertising though this is still a very modest effort and very much a novelty (Halvorson and Karash, 2001).

As it stands today, the space transportation market is primarily the launch industry which is comprised of vehicle manufacturing and various vehicle/payload launches. Until recently, these launches have been primarily into geosynchronous orbits (GSO) which are orbits that follow that of the earth. These orbits are greater than 11,000 nautical miles above the earth and are widely used for global weather mapping and wide-area reconnaissance, as well as for communications. A geostationary orbit (GEO) is a special GSO that remains above the same point of the earth. Launches into lower earth orbit (LEO), which are orbits between 60 and 450 nautical miles above the earth, have emerged as an important though more volatile market segment. Satellites in LEO have a limited view of the earth but can produce high resolution images. These orbits are widely used in telecommunications, navigation, and imaging. Orbits in the 450-11000 nautical mile range are classified as highly elliptical orbits (HEO), and, like lower earth orbits, are considered non-geosynchronous (NGSO). Satellites are launched into orbits that are most appropriate to their functions.

Global launch industry revenues were estimated at $\$ 6.6$ billion in 2002 with the U.S. share at $\$ 2.57$ billion, representing about $39 \%$ of the market. This compares to $\$ 2.35$ billion in 1996 and a $48 \%$ market share in 1996 . The launch industry provides about $6.2 \%$ of global space industry revenues. Industry employment amounted to about 37,500 in 2002, about 3,000 more than in 1996.

Launch industry revenues have been impacted by several factors. Global competition has increased, highlighted by the entry of Russian and Chinese organizations. This has driven launch prices down. The deployment of the Iridium and Globalstar satellite systems into lower earth orbit provided the industry with a major stimulus from 1997 to 2000. However, the subsequent bankruptcy of these companies put a damper on this launch activity. NGSO launches into lower earth orbit were only two in 1996 and seven in 2000 after reaching 18 in 1999. Worldwide GSO commercial launches, on the other hand, were fairly stable over that period, ranging between 20 and 23 per year.

The United States took a step to shore up its position in the commercial space transportation industry with the passage of the Commercial Space Transportation Competitiveness Act of 2000 (Public Law 106-405). In addition to funding some of the agencies involved in space transportation, the legislation addressed the need for a comprehensive assessment of the liability regime for such transport.

\section{Remote-Sensing}

Satellite imaging systems, aerial imaging, and geographical information systems (GIS) are the main components in this industry sector. Recent data for this industry is not readily available but 1998 data put its revenues at 3.3 billion. Though it provided $\$ 2.2$ billion in 1998 revenues, aerial imaging, that is, imaging from traditional aircraft, has been around for decades and is not strictly a space-related industry. Satellite imaging provides raw images and GIS software enhances these images for a variety of applications. Among the applications are meteorology, mapping, urban planning, disaster management, forestry, and insurance assessment. Imaging via remote-sensing satellite systems provide for higher resolution and covers wider areas than is possible with traditional aerial photography. In 2002, commercial remote-sensing satellite data providers totaled approximately 5600 worldwide employees, with about 1100 in the United States, and generated worldwide revenues of about \$230 million. 
Most countries with active space programs have invested in remote-sensing systems and several nations with modest programs are trying to get involved in this industry sector. Countries without space programs are in the market for the images provided by these systems. National security, military and commercial motives are involved. This had led to export controls as well as regulation of imaging targets. Another major issue is the distribution of low-price or free images from public imaging systems in direct competition with commercial providers. The ownership of imaging rights is a further area of controversy. Yet, despite these complications imaging by remotesensing satellites and geographical information software are expected to be growth sectors.

\section{Brief Discussion}

Over the 1996-2002 period for which there is data, cumulative worldwide space industry revenues were in excess of $\$ 517$ billion cumulatively. With cumulative revenues of more than $\$ 431$ billion, the satellite communication component was the largest. Global Positioning Systems, with revenues of slightly more than $\$ 44$ billion, and space transportation, with revenues of almost $\$ 41$ billion, were the next largest space industry components. Remote sensing was the smallest component by far with revenues of about $\$ 1.1$ billion.

During most of this period, annual overall worldwide revenue growth was usually in the 10-20 percent range as was the growth rate for most components and sectors of the space industry. There were some exceptions but the general trend has been highly positive. The U.S. market share of the space industry tends to be large but, in many segments of the industry, the United States is losing market share as the rest of the world increases the degree of competition. Nations of the former Soviet Union and the European Union as well as the People's Republic of China have been increasingly involved in most aspects of the global space industry.

The best estimate of worldwide space industry employment in 2002 was 261,934 employees. The United States accounted for 122, 967 of the total. From the standpoint of jobs, the satellite communications industry component was the largest space industry employer both in the United States and globally.

Some Data for the period 2001-2006

As previously stated, data on global space industries are not so readily available. The Satellite Industry Association, working in conjunction with the Futron Corporation seems to be the best data option. Below are data from its most recent survey. As can be seen, the data overlap that provide in the above presentation. In the earlier report for the Office of Space Commercialization, the information for 2001 and 2002 were forecasts. The data presented in the 2007 report are survey data rather than forecast data which show that global revenue was lower than earlier forecast. Moreover, the 2007 report does not provide any employment estimates.

World Revenues by Sector (in \$billions)

$\begin{array}{llllll} & \begin{array}{l}\text { Ground } \\ \text { Equipment }\end{array} & \begin{array}{l}\text { Launch } \\ \text { Industry }\end{array} & \begin{array}{l}\text { Satellite } \\ \text { Manufacturing }\end{array} & \begin{array}{l}\text { Satellite } \\ \text { Services }\end{array} & \begin{array}{l}\text { Total } \\ \text { Rev. }\end{array} \\ 2001 & 19.6 & 3.0 & 9.5 & 32.3 & 64.4 \\ 2002 & 21.0 & 3.7 & 11.0 & 35.6 & 71.3 \\ 2003 & 21.5 & 3.2 & 9.8 & 39.8 & 74.3 \\ 2004 & 22.8 & 2.8 & 10.2 & 46.9 & 82.7 \\ 2005 & 25.2 & 3.0 & 7.8 & 52.8 & 88.8 \\ 2006 & 28.8 & 2.7 & 12.0 & 62.6 & 106.7 \\ 2001- & 47 \% & & & & 65 \% \\ 2006 & & -39 \% & 26 \% & & \end{array}$

Growth

Source: Satellite Industry Association, June 2007 


\begin{tabular}{lllll}
\hline & & & & \\
& Ground & Launch & Satellite & Satellite \\
2001 & Equipment & Industry & Manufacturing & Services \\
2004 & $30 \%$ & $5 \%$ & $15 \%$ & $50 \%$ \\
2006 & $28 \%$ & $3 \%$ & $28 \%$ & $57 \%$ \\
& $27 \%$ & $3 \%$ & $11 \%$ & $59 \%$
\end{tabular}

Source: Satellite Industry Association, June 2007

Of the $\$ 62.6 \mathrm{~b}$ in 2006 world satellite revenues, $\$ 48.5 \mathrm{~b}$ originated from the broadcasting segment. Satellite TV accounted for $\$ 46.9$ billion of that total as total global satellite television subscribers reached 89 million. Satellite radio, very small by comparison, doubled it revenues from between 2005 and 2006 and increased its subscriber base from 9.4 million to 14.2 in that period. The merger between XM and Sirius, if approved, could provide additional stimulus to the broadcast segment.

Global commercial satellite remote sensing have been positively impacted by new and continuing military and intelligence imagery contracts as well as expanding civil and commercial imagery markets, including online mapping services.

Ground Equipment accounts for the second largest share of industry revenues, driven by the revenue growth in end-user equipment like satellite radio and Direct-to-Home (DTH) TV receivers. These consumer-related products have seen price increases in conjunction with improvements in technology and capabilities. HDTV is still in its infancy accounting for only $2 \%$ of all television channels currently carried by satellite. The number of HDTV channels is projected to grow $35 \%$ annually over the next five years.

By any interpretation of the limited available data, it cannot be said that the space industry is large. In the global economy, it makes a very small mark. However, the various components of the space industry seem to be growing at a fast pace and show promise for the future. The space industry is obviously highly technical and its products, from satellites to satellite TV, spark the imagination. In the following section, this paper will explore the development of new industries and products to add to the space industry portfolio.

\section{The International Space Station And The Development Of New Space Industries}

The industrial activity described above can be categorized as space-related but earth-based in the sense that all the production activity originates on earth using the earth's human and natural resources. Further space-related but earth-based production activity will undoubtedly evolve over the next few decades. However, this section will consider the potential for industrial activity that will largely be extra-terrestrial, in that much, if not all, of it will be space-based. The search for the future of space commercialization appears to be tied to the International Space Station (ISS).

\section{The International Space Station (ISS)}

The International Space Station is being constructed by a consortium of nations on three continents. North America is represented by the United States and Canada. European interests are represented by Russia and the European Union while Japan is the Asian partner. The station consists of laboratory research modules which, it is expected, will be the sites that yield scientific findings and new products. The United States research module, Destiny, was the first to be attached to ISS in 2001. The European Space Agency's research module, Columbus, was to be launched on January 10, 2008 as part of NASA's Atlantis mission which has been canceled because of technical problems. The Japanese module, Kibo, is under construction and is expected to join the others in 2009. Though periodic budget crises in each of the consortium members have slowed down the project, the complex is scheduled for completion in 2010 barring any other financial crises. 
The ISS provides a unique research environment for scientific and industrial inquiry. A recent report on the role of the ISS in space commercialization stated that "Long-duration, human-tended microgravity environment is the most unique, valuable and attractive feature of the ISS as a research laboratory..." (Report to NASA, 2002, p.11). Thorpe (2003, p.172) identifies five basic reasons in support of the ISS research environment:

1. No gravity to upset chemical ingredients during manufacturing.

2. Low dust (microcontamination) environment for delicate material processing.

3. High vacuum environment for airless manufacturing processes.

4. No need for containers to process certain materials.

5. Better vantage point to monitor the impact of pollution on the Earth's environment.

\section{Microgravity Research and its Industrial Potential}

Microgravity research seems to hold the greatest promise for the development of products that would have meaningful commercial value. Some preliminary steps in this direction have been taken through industry collaboration with NASA's Commercial Space Centers (CSC). Originated in 1984 as the Centers for Commercial Development of Space, there are 17 CSCs, all but one of which are university-affiliated. At least 12 of the Centers have already been involved in microgravity projects with dozens of industry partners. These projects have been useful in identifying fruitful lines of inquiry that would be advanced significantly in the laboratory modules of the International Space Station.

The work done at the Centers for Commercial Development as well as the recommendations of national and international organizations such as the National Academy of Science and the European Space Agency has determined that the areas of Biotechnology, Agritechnology and Materials and Processes are most likely target industries for the ISS. Each of these is a broad industrial area that already produces a variety of complex and sophisticated products. What follows is a brief overview of some possible microgravity product and process development research that experts consider to have commercial potential. The science behind this research is outside the knowledge base of most laymen so the presentation is just suggestive of some areas that NASA would like to attract as ISS partners.

\section{Biotechnology}

This area includes the biomedical, medical biotechnology, pharmaceutical, and medical device sectors. These sectors are typically very research intensive. Microgravity research could be useful in the study of human system changes that mimic certain disease processes in aging such as muscle and bone loss and the suppression of immune systems. The development of micro-encapsulation techniques for drug delivery systems is another promising area as is the testing of drugs in microgravity which accelerates the effect of drugs and could help evaluate the consequences of long-term use.

\section{Agritechnology}

This area includes applications that make crops more disease-resistant and of higher nutritional quality. It also includes genetic engineering for the purpose of improving crop yields and food taste. Biologic products and processes are utilized in a many applications such as biopesticides, fermentation, plant and animal diagnostics, and food preservation. Microgravity research could target areas such plant growth and transformation, cell division, gene transfer, and the production of plant antibodies.

\section{Materials and Processes}

This area includes electronic and photonic materials, ceramics, metals and alloys, and polymers as well as the processes of combustion and fluid physics. Microgravity research shows promise for the development of specialty metals that would be difficult to develop under the influence of gravity. Combustion processes for energy 
efficiency, chemical and filtration processes for fuel purification, and catalytic processes for efficient energy conversion are among the processes that can be better understood in a microgravity environment.

These are just a few of the many areas of pure and applied research that could be advanced by microgravity work in the laboratory modules of the ISS. However, though some of this work is already underway in the earthbased CSCs, it is another matter to get companies to move its efforts to the ISS. There are numerous reasons for this that concern both industry representatives and NASA. ISS commercialization workshops were initiated in response to the Commercial Space Act of 1998 (NASA, 2002). These workshops have identified various challenges that industry sees as obstacles to ISS commercialization activities. These challenges have been categorized as policy, technical, financial, and legal.

\section{Obstacles to ISS Commercialization}

Policy challenges include commercial allocation, activity approval, and barriers to free enterprise. The issue of commercial allocation involves the lack of a clear policy with respect to the access of commercial entities to the ISS and its transport systems. Moreover, industry seeks clarity on just which activities will or will not be permitted beyond research and manufacturing which seem to have been given priority. Since space agencies have primarily been involved with non-commercial activities, profit-driven firms are concerned that barriers to free trade such as subsidies and favoring national companies might interfere with profit-driven commercialization and increase the risks for what would already be risky investments.

Technical and program challenges include the time and cost of payload preparation, accessibility to ISS transportation and on-board resources, and the issue of standard setting. Historically, the several factors deemed necessary for non-commercial mission success have required a timeline of 4-8 years and very high costs. For most commercial activities, these time and cost constraint would be prohibitive and industry requires them to be reduced.

Since commercial activities will not be the primary focus of the ISS, there is the issue of timely access to transportation and on-board resources. For example, uncertain flight schedules and the possibility that commercial launches to the ISS would be readily "bumped" are considered by industry sources as being very unfavorable and must be rectified. Another concern is the lack of uniform technical standards for equipment development.

Financial challenges include the development of market outlets for the results of ISS activity. Commercial markets require improved business conditions such as price, quality of service, timeliness, and predictability. Such conditions do not yet exist and must be nurtured if viable commercial markets are to develop. Pricing must be allowed to be market-based, that is, determined by supply and demand factors. This contrasts with the cost-based pricing approaches typical in government arrangements.

Finally, the ISS workgroup identified a substantial number of legal concerns that must be addressed to support the commercialization efforts. Among them are issues relating to liability, tangible and intangible property rights, trade practices, and jurisdiction and adjudication of disputes. For example, in the area of property rights, the desired end state is the protection afforded to owners in the earth-based environment. Yet, the desired assurances are not yet in place (Dinkin, 2004).

From the efforts of the ISS industry workgroup, it is clear that extensive participation of commercial firms is by no means guaranteed. Without such participation, the development of commercially-viable, space-based activities would evolve much more slowly. Thus, NASA and the space agencies representing other ISS nations are addressing the several obstacles identified by industry groups. NASA commissioned a commercial market outreach plan and the OECD has done work on future space markets and on infrastructure for space commercialization (www.OECD.org). 


\section{THE PRIVATE SPACEFLIGHT INDUSTRY}

The capture of the $\$ 10,000,000$ Ansari Foundation X-Prize by Burt Rutan's SpaceShipOne in 2004 seems to have raised the confidence of those entrepreneurs determined to make private space flight a commercial reality. Mooring (AW1 2007) reports that private spending on space-related activities has surpassed that of governments and, in many ways, the industry has shown striking parallels with the early days of civil aviation.

Many of those involved in the private spaceflight industry have been quite successful in other business ventures. Paul Allen, co-founder of Microsoft, financed Burt Rutan's Space Composites which produced SpaceShipOne. Rutan's company, Space Composites, is working on SpaceShipTwo under contract with Virgin Galactic, founded by Richard Branson of Virgin Airways and other ventures in the Virgin Group. To win the XPrize, SpaceShipOne had to reach a height of 62 kilometers with the capability of carrying two passengers on two separate flights within a period of 14 days. The target for SpaceShipTwo is at least 100 kilometers and three paying passengers (Morring, AW1).

The primary business objective of these nascent organizations is to service an emerging space tourism industry which has been pioneered by Virginia-based Space Adventures. Space Adventures has relied on the Russian Space Agency and its Soyuz rockets to send at least five individuals to the International Space Station (ISS) at \$20 million per trip (Morring AW1). The expectation is that there is sufficient consumer demand for short, suborbital flights priced at around $\$ 200,000$ per trip as well as for orbital flights. Further down the road, there seems to be the possibility of trips to the moon. Beyond that, who knows.

Robert Bigelow, successful founder of Budget Suites of America, founded Bigelow Aerospace with the intention of developing inflatable habitats for earth orbit. Target opening date is January 10, 2010. BA has successfully launched two space vehicles, Genesis I and Genesis II in 2006 and 2007. They were launched from a Russian spaceport and controlled from its Mission Control Center in North Las Vegas. Because of rising launch costs, the company has decided to pass on another pathfinding vehicle and is proceeding to its Sundancer project, its first human, habitable spacecraft. Bigelow has offered a $\$ 50$ million prize to the first team to build a vehicle that can successfully dock with the Bigelow Space Habitat for six months or orbit Earth for 60 days. (BA web site, 2007).

On April 10, 2007, Bigelow announced pricing information for prospective customers. For sovereign governments who want to use the inflatable orbiting modules as a training station for its astronauts, the price is $\$ 14.95$ million for four weeks of use and \$2.95 million for an additional four weeks. For companies desiring to conduct industrial research, the modules will lease for $\$ 88$ million per year for a full 350-cubic meter module. Halfmodules could be leased for $\$ 4.5$ million per month. Such prices are highly speculative but indicate a high degree of confidence in the company's ability to deliver. No prices were announced for the inflatable modules as "hotel" rooms (Mooring, AW2).

John Carmack, whose fortune was made on video games, is another who is targeting the market for space tourism. His company, Armadillo Aerospace, based in Texas is developing computer-controlled liquid-oxygen rockets for launching people to over 300,000 feet where they can experience weightlessness (Maier 2006).

Blue Origins, the company created by Amazon.com founder Jeff Bezos, is developing a fully reusable launch vehicle with vertical takeoff and landing capability, also for suborbital space tourism (Maier 2006). Also in the competitive mix for the development of suborbital launch vehicles are Rocketplane Kistler and XCOR, based in California and Oklahoma respectively (Morring AW1 2007).

These companies and several others are members of the Personal Spaceflight Federation. Details of each company's mission and activities can be found through links at www.personalspaceflight.org, the federation's web site. 


\section{CONCLUDING REMARKS}

Though the commercialization of space has made substantial strides in recent years, space industries seem to be below their realistic potential and extremely below what the dreamers envision. However, there are definable industries that are well-established and growing and that growth is likely to continue. Notable has been the increase in the number of nations getting into space activity, if only in the areas of space communications like satellite television. The U.S. market share in many existing space-related industry sectors is declining as global competition increases.

Yet, as has been mentioned, these industries are largely earth-based and the potential for space-based research and production is largely untapped. The future of space commercialization has been focused on the International Space Station which is still to be completed and getting profit-oriented firms to participate in ISS activity has numerous obstacles to overcome. Other areas such as space manufacturing, space mining, and obtaining energy from space are still on the drawing board (Thorpe, 2003). The time horizon is not short.

\section{REFERENCES}

1. Commercial Market Outreach Plan for the International Space Station. A Report prepared for NASA by Equal Three Communications and Booz Allen Hamilton, February, 2002.

2. Commercialization of the IIS: An Industry Perspective. A Report prepared by the Strategic Planning Working Group of the International Space Station Commercialization Workshop 2, April 20, 2001.

3. Commercial Space Transportation Competitiveness Act of 2000. Public Law 106-405, $106^{\text {th }}$ Congress, November 1, 2000.

4. Dinkin, Sam. Property Rights and Space Commercialization. The Space Review, May 10, 2004.

5. Flight, Georgia, Building zero-G boomtowns, February 24, 2006. Downloaded February 27, 2006.

6. Halvorson, Todd and Karash, Yuri. Russia Takes the Lead in Space Age Advertising. Space.com, May 31, 2001.

7. Kramer, Andrew E. Russia Challenges the U.S. Monopoly on Satellite Navigation, nytimes.com, April 4, 2007.

8. Leonard, David. Dennis Tito: NASA Must Embrace Commercialization for Space Tourism to Success, Space.com, October 21, 2001.

9. Maier, Matthew. Millionaires on the Launchpad, CNNMoney, February 27, 2006. Downloaded February 27, 2006.

10. Morring, Jr., Frank. Private Spaceflight Industry Building Toward Takeoff, Aviation Week. Downloaded November 20, 2007.

11. Morring, Jr., Frank. Bigelow Sets Inflatable Space Module Prices, Aviation Week. Downloaded November 20, 2007.

12. Office of Science and Technology Policy. U.S. National Space Policy. Released October 6, 2006. Downloaded from www.ostp.gov.

13. Organization for Economic Cooperation and Development. The Commercialisation of Space and the Development of Space Infrastructure, www.oecd.org. Downloaded June 1, 2004.

14. President's Commission on Implementation of United States Space Exploration Policy. A Journey to Inspire, Innovate, and Discover, June 4, 2004.

15. Press Release. Fact Sheet: U.S.-EU Summit: Agreement in GPS-Galileo Cooperation, White House, June 26, 2004. http:// www.whitehouse.gov/news/releases/2004/06/20040626-8.html.

16. Satellite Industry Association. Satellite Industry Statistics 2002.

17. Satellite Industry Association. The State of Satellite Industries, June 2007.

18. Schwartz, John. Private Space Travel? Dreamers Hope a Catalyst Will Rise From the Mojave Desert, The New York Times, June 14, 2004.

19. Thorpe, Andrew. The Commercial Space Age: Conquering Space Through Commerce. $1^{\text {st }}$ Books, 2003.

20. United States Department of Commerce, Office of Space Commercialization. Trends in Space Commerce. A report prepared by the Futron Corporation, June 2001. 
21. Veenaskay and Sahar Muakasa. Galactic Polity and Business. New York: Advance Research Enterprise, 1988.

\section{NOTES}

